\title{
PANDEMIA Y EL PANDEMONIO DE LA CORRUPCIÓN EN PAÍSES DEL TERCER MUNDO EL ALTO DESVALOR DE LA ACCIÓN Y RESULTADO EN DELITOS DE CORRUPCIÓN EN SITUACIONES DE EMERGENCIA
}

\section{PANDEMIC AND THE PANDEMONY OF CORRUPTION IN THIRD WORLD COUNTRIES \\ THE HIGH FAILURE OF ACTION AND THE RESULT OF CORRUPTION CRIMES IN EMERGENCY SITUATIONS}

Elvis Jorge Alcalde Muñoz*

* Doctor en Derecho y Ciencia Política (UNMSM); Magíster en Derecho - Ciencias Penales (UNMSM); Ex Relator de la Corte Suprema de Justicia del Perú - Sala Penal Nacional. Actualmente se desempeña como Asesor y Docente de Pre y Posgrado de Universidad Femenina del Sagrado Corazón - UNIFÉ, y Universidad de San Martín de Porres - USMP.

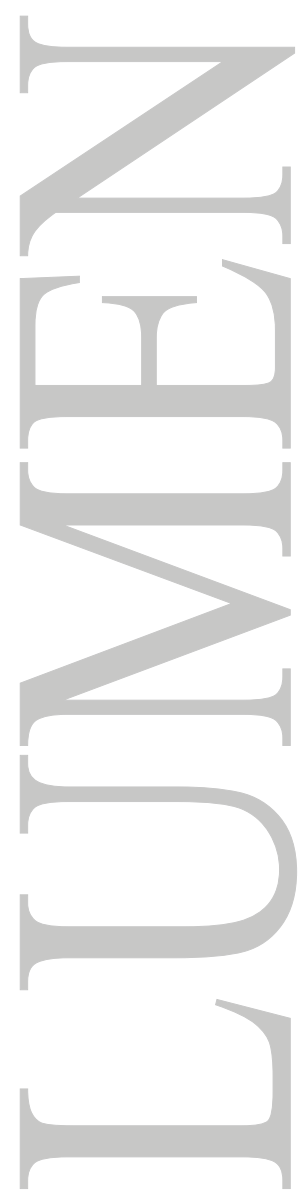




\title{
PANDEMIA Y EL PANDEMONIO DE LA CORRUPCIÓN EN PAÍSES DEL TERCER MUNDO \\ EL ALTO DESVALOR DE LA ACCIÓN Y RESULTADO EN DELITOS DE CORRUPCIÓN EN SITUACIONES DE EMERGENCIA
}

\author{
PANDEMIC AND THE PANDEMONY OF CORRUPTION IN THIRD WORLD COUNTRIES \\ The high failure of action and the result of corruption crimes in emergency situations
}

Elvis Jorge Alcalde Muñoz

\begin{abstract}
RESUMEN:
El presente artículo, otorga una perspectiva criminológica en relación al derecho penal moderno y la figura del desvalor de la acción y el resultado en delitos especiales como la corrupción en situaciones de emergencia nacional, entendiendo a la figura del desvalor como parte del elemento antijurídico del delito. Por otro lado, aborda la temática de la opinión pública como factor importante en la valoración positiva o negativa de un hecho presuntamente delictivo y su participación como grupo de presión y/o de interés ante las autoridades del Estado frente a un hecho de relevancia social.
\end{abstract}

\section{PALABRAS CLAVE:}

Desvalor de la acción, desvalor del resultado, antijuridicidad, corrupción, opinión pública..

\begin{abstract}
:
This article gives a criminological perspective in relation to modern criminal law and the figure of the devaluation of the action and the result in special crimes such as corruption in situations of national emergency, understanding the figure of devaluation as part of the unlawful element of the crime. On the other hand, it addresses the issue of public opinion as an important factor in the positive or negative assessment of an allegedly criminal act and its participation as a pressure and / or interest group before the State authorities against a fact of social relevance.
\end{abstract}

KEY WORDS:

Devaluation of the action, devaluation of result, unlawful, corruption, public opinion.

SUMARIO: I. Introducción; II. Finalismo y Antijuridicidad; III. Desvalor de la Acción y resultado; IV. Emergencia sanitaria y corrupción; V. La Opinión pública y el delito; VI. Conclusiones; VII. Referencias

\section{INTRODUCCIÓN.}

En el presente artículo, busco analizar esa secuencia en el fundamento de la gravedad del hecho cometido por el funcionario que aprovechando de su cargo obtiene un beneficio indebido en situaciones de emergencia nacional en perjuicio de la sociedad. De manera especial señalaremos el fundamento por el cual cualquier delito con aprovechamiento de un cargo público tiene una valoración negativa por la sociedad, lo que en buena cuenta se denomina a mí entender desvalor de la acción y resultado.

Al término de la segunda guerra mundial se entendió que el mundo era un lugar donde ser podría cometer delitos tan graves como el exterminio de personas, hecho que dejó a la comunidad internacional impactada y que con el pasar del tiempo tanto en Europa y otras latitudes se trató de crear entidades globales y legislar en procura de evitar hechos desastrosos en el futuro. Sin 
embargo, si bien las normas trataron de regular aspectos de los conflictos armados internacionales, en si no pretendían evitar que el ser humano y en particular los Estados puedan incursionar en actos retorsivos, y de enfrentamientos ya que se entendía que el ser humano es un ser social pero no exento de caer en actos conflictivos entre ellos. Por ello se reguló en el sentido de reglamentar las reglas de los conflictos armados internacionales, es decir evitar actos que atentaran contra población vulnerable y evitar la perfidia y el uso de medios militares impropios y que atenten contra la dignidad humana.

Paralelo a ello, se tomó conciencia sobre el procesamiento y juzgamiento de autoridades que hubiesen cometido actos delictivos particularmente graves, sin embargo, existía la disyuntiva sobre si estas personas debían de responder como tales, en su calidad de funcionarios y de manera directa por sus crímenes. Este fue el primer punto de discusión ¿Cómo hacer responsable a un alto funcionario que no había estado en la escena del crimen? Los tribunales de Nuremberg en la Alemania de la posguerra sentaron un precedente importante ya que se establecía la categoría de "organización criminal" a grupos administrativos militares que estaban dirigidos por autoridades militares (algunos reconocidos oficialmente y otros paramilitares) como la Gestapo, las SS, y grupos de Asalto. Esto fue el inicio para una toma de conciencia jurídica y entender que autoridades tanto administrativas como militares que en ejercicio de sus funciones puedan cometer actos delictivos son susceptibles de ser juzgados y encontrar en ellos responsabilidad penal, aunque no hubieran participado directamente en los hechos. Encontrar el fundamento jurídico penal de la autoría mediata fue lo complicado.

Así, el delito entendido como toda acción penalmente relevante, típica, antijurídica y culpable que trae como consecuencia natural una sanción penal para el infractor, dicha estructura ha ido evolucionando con el pasar del tiempo y adquiriendo una configuración de acuerdo a la doctrina que se acoja. Los causalistas han contemplado el delito como acción y resultado - causa y efecto - movimiento físico y consecuencia y que Von Liszt lo conceptualizó con bastante detalle, ello también ha ocasionado polémicas con las doctrinas finalistas del derecho penal, tanto es así que la terminología de "autoría intelectual" para el mandante fue identificada como inducción o instigación, mientras que para la corriente finalista fue tratada como un caso especial de coautoría. Es verdad que de acuerdo a las diferentes tendencias que en su mayoría son alemanas, el derecho penal ha tenido diversos cambios y posturas en cuanto a la tratativa de sus figuras jurídicas, ello en procura de buscar la mejor tipificación y sanción penal para el infractor, de manera especial para aquellas personas que ostentando cargos públicos o de dirección aprovechan dicho status para cometer delitos en perjuicio de la sociedad. Sin embargo, el futuro del delito y el derecho penal se ve con mayor detalle en lo relacionado a la prevención y la intervención punitiva en menor grado. Por lo que los controles informales hoy en día deben tomar un protagonismo más decisivo en las sociedades. La familia y la escuela con apoyo del Estado son imprescindibles en la formación de individuos alejados de conductas desviadas. En las últimas décadas el delito y la criminalidad se ha especializado y se ha estructurado en aparatos de poder utilizando en sus filas rostros juveniles, por lo que se ha vuelto transnacional y global, en esa línea, la sociedad ha identificado al delito como un estigma y un fenómeno para lo cual el Estado tiene que combatir y reprimir severamente. Los políticos hacen eco de estos pedidos y se producen las promesas de punición elevada, pero la labor preventiva no es muy popular y tampoco puede visualizarse con premura sino a largo tiempo por ello demora su aplicabilidad en las sociedades modernas. Algunos países europeos como Suecia, Alemania, y Holanda han reducido sus índices criminales considerablemente debido a políticas públicas de prevención y reinserción de condenados a la sociedad.

\section{Finalismo y Antijuridicidad}

La doctrina finalista del derecho penal ha establecido el dominio final de la acción. El delito ya no es resultado de una mera acción mecánica, sino que obedece a un aspecto volitivo frente al suceso, 
la intencionalidad pasa a ser un aspecto trascendental en la comisión del delito. Ello a su vez repercute en la estructura delictiva y los elementos del mismo, así el dolo y la culpa ya no es más analizada en la fase final, sino que toma un interés fundamental y se contempla con mayor detalle en la tipicidad, específicamente en la tipicidad subjetiva. Recordemos que para los causalistas como su objetivo principal era dilucidar la causa física que produce el delito, la intencionalidad era debatida en la culpabilidad. Pero, debemos tener presente que todos estos cambios de concepción de doctrina a doctrina también obedecen a las nuevas modalidades delictivas que han ocurrido desde comienzos del siglo XX en adelante donde el autor de un delito no necesariamente tiene que estar en la escena del crimen, sino que puede conducir los hilos del delito desde lejos, así existen el autor mediato por aparato de poder, el mandante y el sicario, y otras formas de criminalidad con las nuevas tecnologías. En 1961, la sentencia del caso Adolf Eichmann en Israel, trajo a colación precedentes jurisprudenciales importantes para la justicia penal internacional y uno de ellos era la existencia de responsabilidad penal del alto funcionario de un régimen dentro de la conformación de lo que se denominó aparato organizado de poder, y por lo cual un eslabón de un engranaje o funcionario de régimen puede ser capaz de cometer delitos, aunque no de manera directa, y ser sancionados por la justicia a título de autoría mediata. Eichmann fue imputado como el operador logístico, el arquitecto del exterminio de miles de personas durante la segunda guerra mundial, debido a que en la estructura de la "Solución final" de Wannsee (1942) era fundamental la organización detallada y el envío de miles de personas a la muerte, consideradas ya por el derecho internacional población desvalida o vulnerable, que luego fue elevado dicha catalogación a un status jurídico de protección especial por los convenios de Ginebra de 1949. En esa línea, en el juzgamiento europeo continental siempre se ha respectado el principio de imputación penal y el derecho a la defensa de un procesado, sea cualificado (funcionario público) o no. Es importante precisar que el incidente del traslado de Eichmann hacia Israel provocó un incidente internacional con la República Argentina debido a la forma del traslado que fue catalogada como un mero secuestro, y que causo el reclamo airado de este último ante las Naciones Unidas por la intromisión en su territorio. También se debe señalar que ya existían comentarios y algún antecedente previo sobre la negativa de Argentina a entregar formalmente personajes controvertidos y con problemas judiciales internacionales.

Adolf Eichmann fue condenado finalmente a la pena capital, luego de un juicio que fue considerado por especialistas como previsible en el resultado, si bien es cierto se actuó bajo las reglas de un juicio europeo continental donde existió fiscal acusador, un colegiado de jueces y los debates orales en el cual primó prueba documental y testimonial, así como la publicidad del proceso ya que fue transmitido vía medios de comunicación sin embargo eran pocas las posibilidades de que el denominado "asesino de escritorio" pudiera salir librado de las imputaciones. Uno de los argumentos de defensa más recurrentes que elabora un funcionario o autoridad acusada de crímenes durante un gobierno (salvo que sea primer mandatario) es el de la obediencia debida, es decir la recepción de una orden que debe de cumplirse sin miramientos por el hecho mismo de la conformación de la organización que, aunque no necesariamente fuese militar tiene un perfil vertical en que los superiores ordenan y los inferiores en las cadenas de mando ejecutan. Así el funcionario acusado puede estar en el mando medio, mando logístico, brazo legal, soporte técnico, organizador, etc.

La teoría del delito nos ha enseñado que tanto a nivel interno como internacional, el hecho delictivo tiene una estructura de elementos y que la culpabilidad precisamente para los finalistas es un elemento que también presenta eximentes de relevancia y que dichas eximentes lindan con causas inculpatorias y causas exculpatorias, entendiendo a mi criterio que las segundas son más enunciativas y donde precisamente se muestra la obediencia debida como eximente de la culpabilidad y por lo tanto la eliminación del delito. La eximente existe jurídicamente, sin embargo, no se aplica en todos los casos, por ello hay que señalar que opera siempre y cuando el receptor de la orden no haya tenido la posibilidad de entender el carácter delictuoso de la orden, caso contrario estaría siendo co-autor o partícipe del crimen. Teniendo presente que generalmente, donde existe 
aparato organizado del poder o estructuras verticales los delitos se consuman con la intervención de varias personas y en cuyo denominador común existe hecho de corrupción, fraude y adulteración, ello precisamente porque se trata de borrar evidencia, alterar escenarios de los delitos cometidos.

\section{El fenómeno delictivo}

\begin{tabular}{|c|c|c|c|}
\hline \multicolumn{4}{|c|}{ EL FILTRO DEL DELITO } \\
\hline \multirow{2}{*}{ Acción } & Tipicidad & $\begin{array}{c}\text { Antijuridicidad } \\
\text { (Desvalor) }\end{array}$ & Culpabilidad \\
\hline
\end{tabular}

- Señala los elementos del delito, y el orden en que debe analizarse para realizar el filtro jurídico penal adecuado de un hecho presuntamente con relevancia penal.

Hannah Arendt (1963) cubrió las primeras sesiones del proceso penal a Eichmann, y por lo cual también escribió la obra "Eichmann en Jerusalén. Un estudio sobre la banalidad del mal". Arendt dejó entrever que existían personalidades con características psicopáticas y que por lo general eran propios de estos funcionarios y autoridades que cometían graves delitos en ejercicio de un poder determinado, por lo general eran personas comunes, ciudadanos ejemplares ante la sociedad, buenos padres, esposos amorosos, por ello, al parecer estos hombres banales en el fondo contenían una entraña perversa. En esa línea Robert Hare (1974) señala "suelen ser insensibles y hedonistas, de muy acentuada inmadurez emocional, carentes de responsabilidad y de juicio lúcido, y muy hábiles para racionalizar su comportamiento a fin de que parezca correcto, sensato y justificado" (p.11). A decir de lo precitado, podemos decir también que estos personajes aprovechan su posición, su nivel jerárquico dentro de la sociedad para obtener un provecho y lograr sus objetivos sin importar el daño que pudieran causar, por lo que existe una falta de empatía absoluta con el prójimo, y por lo demás también son incapaces de experimentar sentimientos de satisfacción con actividades sencillas de la vida cotidiana por lo que necesitan aglutinar la mayor cantidad de dinero y bienes materiales.

La comunidad internacional y la sociedad europea de principios y mediados del siglo XX tenía características conservadoras, después de la gran guerra se crearon organismos internacionales con la firme convicción de resurgir de los escombros, de una Europa destruida. Uno de los organismos que se creó para estos fines fue el Consejo Europeo de Derechos Humanos, así como las Naciones Unidas, pero a su vez se dio el nacimiento de una Justicia Humanitaria incipiente donde existió tribunales ad-hoc para juzgar precisamente a altas autoridades que hubieran cometido delitos graves a nivel internacional como por ejemplo los tribunales de Tokio y los tribunales de Nuremberg (1945). Estos tribunales si bien eran momentáneos, pertenecían a la justicia internacional, situación que años posteriores se realizó de manera similar con el Tribunal de Jerusalén donde se procesó y condenó a Eichmann como parte de una Organización criminal y autor mediato de crímenes contra la humanidad (1961). Es necesario tener presente que ya años antes se elaboró la doctrina de autoría mediata por aparatos de poder por Claus Roxin (1950), hecho que fue tomado también en la jurisprudencia internacional con la sentencia precitada. Aquí precisamente se empiezan a consolidar las teorías finalistas del derecho penal. Posteriormente diversos tratadistas han reconocido la importancia del finalismo para la calificación de la autoría en un delito, tal es el caso la doctrina señala que:

Si el fundamento de la coautoría es el llamado dominio funcional del hecho, lo importante no es ya solamente la intervención en la ejecución del delito, sino el control o dominio del hecho que un individuo tenga, aunque no esté presente en su ejecución. (Muñoz, F. 1993 p.390) 
Por otro lado, las conductas jurídico penales imputables a estos funcionarios tienen que pasar el filtro de la teoría del delito, no solamente el juicio de tipicidad, es importante esta distinción ya que en el primer caso debe verificarse todos los elementos del delito para que el hecho sea delito, mientras que en el segundo supuesto el juicio de tipicidad o proceso subsuntivo solamente abarca la adecuación del hecho al tipo penal, por lo que aún faltaría verificar la existencia de antijuridicidad y culpabilidad. Por ello la obediencia debida como argumento de defensa debe ser analizada en el último tramo de los elementos del delito como ya lo señalamos líneas precedentes. Las imputaciones contra estos funcionarios por lo general son graves, de trascendencia, actos de corrupción, falsificaciones, homicidios, blanqueo de capitales, etc. por lo que la antijuridicidad en estos hechos constituye aquella acción típica que va en contra del ordenamiento jurídico vigente, y que en gran mayoría no tendrían causa de justificación que pueda anular este elemento antijurídico. Entre las causas de justificación se ha generalizado, por ejemplo, la legítima defensa, el estado de necesidad justificante, el consentimiento, el ejercicio legítimo de un cargo, deber, derecho u oficio, y que, si bien son argumentos de defensa, en la práctica con las pruebas de cargo son desbaratadas. También se debe señalar que, para la corriente finalista del derecho penal, aquí también se analiza el desvalor de la acción que en buena cuenta se pondera de acuerdo a la sociedad vigente y a la situación coyuntural imperante.

\section{Desvalor de la acción y resultado}

Para comprender la figura del Desvalor de la acción y resultado en un delito debemos tener presente a la sociedad como grupo humano dentro de un país, como un elemento fundamental, por ello, previamente señalaremos una pequeña reseña histórica sobre el particular. La segunda guerra mundial ocasionó una serie de consecuencias en el campo jurídico penal internacional, lo que con el tiempo se denominó derecho internacional humanitario, pero estas reformas de trascendencia fueron posibles debido a que la población europea impulsó a través de los gobernantes fuertes reformas para resarcir y evitar que en el futuro se suscitaran nuevos hechos lamentables para los países europeos. Viena, París, Dresde son ciudades cuya población quedó devastada por la guerra, pero además entendió que nunca más debía repetirse hechos que involucraran exterminio, genocidios, saqueo y corrupción. Así no sólo las pérdidas son materiales, y humanas, sino que toda una generación de cultura y esplendor intelectual pueden verse afectados. Recordemos a Sigmund Freud que producto del inicio del conflicto armado se interrumpió sus investigaciones para ser objeto de represión por parte de la Gestapo, finalmente pudo salir de Viena al exilio, donde finalmente falleció en Londres en 1939. Otro ejemplo fue Albert Einstein quien producto del conflicto armado tuve que salir de Europa, para finalmente terminar en los Estados Unidos de América donde se desempeñó como docente en el Instituto de Estudios Avanzados de Princeton.

Similar afectación en el aspecto intelectual sufrió Sabina Spielrein, famosa por sus estudios en medicina -psiquiatría, sin embargo, cuando regresó a Rusia, a su ciudad natal Rostov On Don, 1941, fue recluida en un campo de exterminio nazi por tener un origen judío, donde fallece cuando el mundo sentía con rigor la amenaza del nacional socialismo alemán. A propósito de ello, no puedo dejar de mencionar la evidencia histórica que en relación a Sabina existió una confrontación de ideas tanto intelectuales como culturales entre Carl Jung y Sigmund Freud, y que la historia ha registrado el factor del distanciamiento entre los precitados intelectuales, por lo que estos tres personajes se cruzaron en algún momento de sus vidas. Sólo como acotación de lo precitado, al respecto Frey-Rohn (1993) señaló "Jung también rechazaba firmemente toda extensión del concepto sexual a la actividad autoerótica infantil. Los juegos sexuales y el placer obtenido eran esencialmente diferentes en los niños de los adultos" (pp. 151 y 152). Por todo ello, el daño que se causa a la humanidad con acciones criminales es incalculable, la liga de naciones lo entendió así, las Naciones Unidas lo entendió así, el Consejo Europeo de Derechos Humanos lo entendió así, y los tribunales internacionales especiales creados para hacer justicia internacional también lo entendió, por eso la Europa destruida se levantó de los escombros a partir de 1946 en adelante. La sociedad europea 
valoró la catástrofe como un daño de tal magnitud que debía ser enfrentado castigando a los presuntos responsables, pero también estableciendo organismos y normativa internacional que en alguna medida traiga seguridad, restablezca la paz y la sostenga en el tiempo para beneficio de la comunidad, así nace en la dogmática penal la valoración del hecho que significa una ponderación equilibrada que realiza una población en un espacio y tiempo determinado sobre acontecimientos que pueden o no ser nocivos para una sociedad. Esta ponderación se traduce posteriormente en normatividad, y específicamente en sanciones penales, cuando es recogida por el Estado. Por ello debemos tener presente que la valoración negativa o positiva que se trabaja en la antijuridicidad tiene como origen la afectación de un hecho que sufre la sociedad, así hoy en día, cuando se habla de delitos si bien algunos delitos tienen como agraviado a una o dos personas, y otros delitos afectan a intereses colectivos, sin embargo, el impacto social es uno solo, la sociedad da su veredicto y se traduce en la regulación de ese hecho grave como delito y una sanción penal ejemplar. Así, en los tipos penales donde el sujeto activo es un alto funcionario público o una autoridad militar, conmociona con mayor fuerza a la sociedad, ya que en derecho el funcionario público, la autoridad tiene un mayor escrutinio público, y su comportamiento debe ser modelo a seguir y estar al servicio de la colectividad. Por ello el reproche penal en ellos es mayor.

Más técnicamente, en los delitos dolosos para que existe la denominada consumación se tiene que verificar dos circunstancias especiales como son: la acción y el resultado. La acción tiene una significación de relevancia penal y que al no evolucionar recibe la denominación de tentativa, actos ejecutivos o tentados, por ello en la tentativa el autor comienza la ejecución de un hecho delictivo sin llegar a consumarlo. Los ilícitos dolosos admiten tentativa debido a la intencionalidad deliberada del autor para cometer el delito, así cuando estas acciones son frustradas y se quedan en hechos tentados también son sancionadas penalmente, aunque con una pena atenuada. La acción penalmente relevante que sólo deviene en un hecho tentado tiene un reproche importante de la sociedad ya que se trata de un acto intencional, voluntario y consciente del autor, ello debido a que si no fuera frustrado se hubiera consumado el delito. En consecuencia, el desvalor no es más que la pérdida de valor de un hecho, es decir una valoración negativa de un hecho que la sociedad asigna a los ilícitos tanto en la modalidad de acción, y con mayor fuerza se verifica ese desvalor cuando se da un resultado.

De otro lado, en los delitos culposos a nuestro criterio, sí es posible hablar de desvalor de la acción y resultado, pero como una unidad, ya que en los ilícitos culposos no se admite la tentativa, sólo el resultado derivado de una acción imprudente, negligente, de impericia o por transgredir reglamentos, y que también es desaprobada por la sociedad.

Sólo como un ejemplo final, nos podemos ubicar en el Estatuto de Roma de la Corte Penal Internacional que entró en vigencia en el año 2002 después del cierre del tratado por parte de los países miembros, y en la cual se ha regulado como crimen de importancia dentro del derecho internacional humanitario el cual se refiere al reclutamiento de niños soldado situación que se ha visto con mayor incidencia en países socialmente subdesarrollados como algunos países africanos, siendo Ruanda, Sudáfrica y el Congo, ello ha merecido su regulación legal y la sanción penal severa para los infractores de esta normativa. Así en el año 2012 se ha confeccionado la primera sentencia de este tribunal internacional sancionando a una autoridad jerárquica militar por estos hechos precisamente en una nación africana y que hoy en día las Naciones Unidas y la comunidad en su conjunto ha considerado como crimen de guerra incluso.

\section{Emergencia sanitaria y corrupción}

Estando a la coyuntura actual, y que la sufrimos la mayoría de habitantes del planeta, los Estados de emergencia se han generalizado a nivel mundial, medidas restrictivas de derechos fundamentales como la libertad han sido necesarios implantar como paliativo de una pandemia 
que azota a los pueblos del mundo. En estos primeros meses del año 2020 se ha escrito mucho al respecto, posturas a favor y en contra de las medidas implantadas por los gobernantes en el afán de detener una enfermedad que ya ha cobrado la vida de miles de personas. Sin embargo, lo cierto es que la enfermedad y las medidas restrictivas han ocasionado un problema tanto a nivel social y económico sobre todo en los países con un pobre índice de crecimiento y desarrollo por lo que incluso se estima que a largo plazo la cura podría traer un costo social casi tan elevado como la enfermedad. Cuando catástrofes como desastres naturales, conflictos armados internos o internacionales o crisis sanitarias, epidemias o pandemias afectan a países en vías de desarrollo, ello produce una atraso social y financiero muchas veces irreparable.

Lo precitado es importante resaltar, ya que el tema que nos ocupa en el presente artículo se refiere a la situación en que el funcionario público o autoridades con el poder que ostentan dentro del Estado puedan abusar de su status y cometer actos ilícitos que le pudieran generar ganancias, beneficios o situaciones ventajosas en desmedro de los intereses de la sociedad. Ya, en líneas precedentes hemos analizado el título de autoría por la cual debe responder el funcionario o autoridad de gobierno, ahora veremos el fundamento del mayor reproche social de su hecho. El Perú como otros países de tendencia europea continental han regulado en sus legislaciones penales tipos penales relacionados al aprovechamiento indebido de un cargo público para obtener una ganancia indebida y es lo que normativamente se denomina delitos de función o también delitos contra la administración pública, donde el agraviado no es una persona en particular, sino el Estado, pero que al final ese desmedro o daño se trasluce en la sociedad. Por lo general los actos de corrupción engloban las modalidades delictivas precitadas ya que constituyen en el fondo relaciones de intercambio de favores que benefician a las partes intervinientes de manera ilegal y en perjuicio del Estado y que, por la misma naturaleza de estas tratativas, son ocultas, subrepticias. En ese sentido se pronuncia Caciagli (1996) señaló "es fundamental y vital para las prácticas corruptas el ser secretas y ocultas" (p. 84).

También es necesario tener presente que el funcionario público o postulante a funcionario público no sólo se vale de actos de corrupción para enriquecerse, sino que también utiliza clientelismo, figura que ha sido estudiada por diversos especialistas pero que en el fondo entraña la búsqueda constante de favores políticos, aliados de poder, generalmente estas relaciones de clientelismo son más abiertas, ya que se requiere un número considerable de adeptos, mientras que la corrupción es más reservada ya que constituye tipos penales específicamente regulados de manera cerrada por las legislaciones penales de los países, tales como prevaricato, malversación de fondos, peculado, cohecho, tráfico de influencias, etc. Pero, esto es más delicado de lo que se piensa debido a que, por lo general los delitos precitados engloban a su vez para su consumación la comisión de otros ilícitos penales, tales como falsificación de documentos, usurpación de cargos, blanqueo de capitales, entre otros.

Cuadro $\mathrm{N}^{\circ} 02$

Corrupción vs Clientelismo

\begin{tabular}{|c|c|}
\hline \multicolumn{2}{|c|}{ Variantes de la corrupción } \\
\hline 1) Corrupción & $\begin{array}{l}\text { - Prevaricato, malversación de fondos, } \\
\text { peculado, cohecho } \\
\text { - Actos ocultos }\end{array}$ \\
\hline 2) Clientelismo & $\begin{array}{c}\text { - Búsqueda de favores políticos, aliados } \\
\text { de poder. } \\
\text { - Actos abiertos }\end{array}$ \\
\hline
\end{tabular}


- Establece la funcionabilidad y variantes del intercambio de favores en relaciones nocivas dentro del aparato estatal y que por lo general se busca la obtención de un provecho ilícito en desmedro de los intereses de la sociedad.

Por otro lado, también el funcionario público tiene prerrogativas especiales no por su condición de persona, sino por la majestad del cargo que ocupa. En los países europeos continentales por una ficción legal los funcionarios públicos son considerados el ejemplo más importante de la sociedad, por ello representan a su pueblo, en tal sentido deben tener antecedentes limpios, intachables, pero también deben observar una conducta impecable, es por eso que, por ejemplo, el derecho a la intimidad en ellos está recortado en las esferas públicas. Lo precitado es importante resaltar ya que el escrutinio de la sociedad va significar un mayor rigor para los funcionarios públicos. El tratamiento jurídico penal en delitos comunes siempre es distinto del funcionario público respecto de una persona común, así en los delitos siempre se consigna si el agraviado es funcionario público constituye una agravante para el autor del delito, casol contrario, si el autor de un delito es un funcionario público de igual manera es agravante para el precitado funcionario por lo que el reproche es mayor y la pena se agrava. Las legislaciones penales en el mundo tienen un título especial dentro de sus normas relativas a los delitos especiales de función en que el autor del delito tiene que tener una cualificación especial, ser funcionario o servidor público y que generalmente se los identifica como delitos contra la administración del Estado, esto es importante resaltar porque en todos estos delito, salvo excepciones raras, el agraviado es el Estado, y si uno revisa estos delitos, las penas siempre son un tanto más elevadas, son delitos agravados en realidad, precisamente por la calidad del autor, ser representante del Estado y aun así atentar contra el mismo ente y en correlación contra la sociedad.

Lo precitado es importante ya que si en situaciones normales, estos delitos de función son agravados per se, con mayor razón y en mayor intensidad tendrían que ser sancionados los delitos de función cometidos en escenarios particularmente graves como una crisis nacional, un Estado de Emergencia, un Estado de sitio, un conflicto armado internacional, una pandemia, etc. Esto es lo que antaño se solía llamar "delitos calamitosos" y que consistía en que el delincuente se aprovecha de una situación apremiante de su prójimo para arrebatarle un bien, para robarle o cometer algún latrocinio contra el desvalido. Estos actos de ser cometidos contra ciudadanos de un país que está sufriendo una catástrofe nacional, más aun siendo autoridad o funcionario público merece una valoración negativa (desvalor de la acción y resultado) sumamente severa por parte de la sociedad y que se debe traducir en sanciones penales elevadas. Ya en diversos países del oriente se ha establecido la imprescriptibilidad de los delitos de corrupción y la pena de muerte, por ello debemos tener presente que el funcionario tiene el erario nacional y los poderes otorgados para disponer de los bienes del Estado, por ello su responsabilidad es de mayor intensidad.

\section{La Opinión pública y el delito}

La opinión pública es un factor determinante para una conciencia social regulatoria y punitiva ante el aumento de la criminalidad, y que con el tiempo dicha opinión pueda ser recogida por la normatividad penal de cada país. Si bien es cierto, la sociedad no debe influir como grupo de presión negativo en la aplicación de la justicia ni en la labor legislativa, sin embargo, si debe servir para que los legisladores tomen sus comentarios como una pauta a seguir al momento de regular nuevas conductas típicas en beneficio de la comunidad. La opinión de la sociedad muchas veces desencadena en grupos de interés y grupos de presión que de una u otra forma influye en la toma de decisiones por parte del Estado, así, existen grupos de poder formalmente establecidos y que interceden ante funcionarios públicos, pero de manera legal y que están reconocidos por el Estado, éstos últimos son los denominados "gestores de intereses" y que tienen su marco regulatorio respectivo. 
Los colectivos sociales son importantes ya que propician en la agenda nacional un debate determinado ya que constituyen pequeños núcleos de personas que llevan la voz de una sociedad o comunidad, así existen por ejemplo grupos de poder o grupos de presión y grupos de intereses. Los grupos de presión constituyen un conjunto de personas con intereses comunes que fuerzan las decisiones que toma el Estado a su favor, ejemplos de estos grupos los encontramos en los sindicatos, asociaciones gremiales, asociaciones profesionales, sindicatos, federaciones, también existe grupos de presión internacionales como Amnistía internacional, entre otros. Por otro lado, existen aquellos grupos de presión que realiza un trabajo técnico bajo una remuneración y que lleva la voz de un determinado grupo social ante las autoridades gubernamentales en el caso de EEUU se les denomina Lobbies, y en el caso peruano "gestor de intereses".

El denominado gestor de intereses en el Perú tiene su base normativa en la Ley $N^{\circ} 28024$ que data del año 2003. Los gestores de intereses o Lobistas tienen que estar registrados en la SUNARP e informar sobre sus actividades, además sabemos que es muy sensible la relación entre los grupos de interés de un sector de la sociedad y las autoridades que toman decisiones públicas, por ello con la normatividad se busca un proceso transparente, bien fundamentado y con argumentos que permitan al funcionario público se ilustre y tome las decisiones más pertinentes. Recordemos que los gestores pueden interceder en intereses propios o intereses de terceros. Los gestores pueden ser personas naturales o jurídicas, nacional o extranjero, pero necesariamente deben estar inscritos en el Registros de Gestores de la SUNARP en el caso de que sus actividades la ejerzan en el Perú. Este marco regulatorio es importante para evitar posibles actos indebidos o corruptelas en el proceso de representar a un grupo social ante altos funcionarios del Estado llevando una propuesta determinada.

Así también, los grupos de presión, al momento de plantear sus propuestas frente a la autoridad sobre una coyuntura específica, pueden utilizar técnicas de negociación legítimas o ilegítimas, dentro de las primeras está por ejemplo la persuasión utilizando la negociación directa o indirecta (por medio de un gestor). Estas negociaciones ante el poder político o de gobierno pueden ser amistosas o polémicas, mucho tiene que ver aquí las estrategias de persuasión, poder de convencimiento, etc. De otro lado, nos encontramos con técnicas de intimidación o corrupción, lo que denominábamos líneas arriba negativas o ilegítimas. Estas técnicas se relacionan con actos incluso delictivos donde prima la violencia, la amenaza a las autoridades del poder de gobierno, protestas en las calles, vandalismo, así también como actos ilícitos como cohecho, tráfico de influencias buscando la decisión favorable, generalmente estos actos de corrupción son ocultos, no existe transparencia en los acuerdos.

\section{Conclusiones}

1) El finalismo es la corriente del derecho penal que ha servido para que funcionarios de élite pueden ser sancionados penalmente como autores por hechos delictivos a nivel mundial, aunque su intervención en el delito no haya sido directa, lo que ha permitido tener justicia y sobre todo revolucionar el derecho penal y ponerse a la altura de la criminalidad organizada. Así también el finalismo brinda un especial interés a la intencionalidad del sujeto infractor por ello en hoy en día el dolo y la culpa se analiza en la tipicidad y ya no en la culpabilidad como era antaño con las corrientes causalistas.

2) El Desvalor de la acción y resultado es una categoría que se estudia dentro del segundo elemento del delito (Antijuridicidad), sin embargo, es necesario precisar que nace en la sociedad, es decir el grupo humano es quien valora positivamente o negativamente un hecho sucedido en una coyuntura determinada y la califica como nocivo o no. Así, posteriormente a través de representantes o grupos de presión se presenta ante la autoridad de gobierno y plantea la regulación de una norma o política pública que busque el bienestar de la población. 
3) La valoración negativa de un delito de función tiene un mayor reproche penal cuando los ilícitos se cometen en situaciones calamitosas, es decir en estados de emergencia o de conflictividad interna o externa, ello debido a que demuestra el poco aprecio del funcionario frente a la sociedad y la falta de empatía ante el prójimo. La sociedad comprende que estos hechos tienen un significado de gravedad y que deben ser castigados severamente, recordando que el funcionario o autoridad de gobierno tiene un especial deber de servicio para con sus conciudadanos, es la razón de ser de su cargo y a ello se debe.

4) Los actos de corrupción y el clientelismo son dos categorías dentro del fenómeno criminológico que tienen características disimiles, pero que en el fondo causan un grave daño a la sociedad. Los actos de corrupción generalmente son ocultos, enmarcan delitos penados por la ley como por ejemplo el soborno, el tráfico de influencias, el peculado, tráfico de influencias, etc., mientras que el clientelismo son actos abiertos en que los candidatos o funcionarios en ejercicios buscan gran cantidad de adeptos o aliados, y que ello lleva un trasfondo de intercambio de favores una vez que se ejerce el cargo público. Ambas categorías a largo plazo traen un perjuicio para la colectividad.

5) La forma en que la sociedad transmite la valoración negativa de un hecho ante las autoridades políticas o de gobierno es por medio de representantes o grupos de presión. Estos grupos de presión pueden ejercer en alguna medida influencia sobre los sectores de gobierno para que pueda atenderse su pedido y regularse una normatividad que, por ejemplo, tipifique un hecho delictivo o lo penalice con mayor severidad.

6) El derecho penal busca a futuro delimitar las verdaderas responsabilidades del sujeto infractor de la ley penal, siempre en la medida de su hecho, por ello busca regular adecuadamente los tipos penales. Mucho se ha escrito sobre la despenalización, sin embargo, ésta no será posible en su totalidad mientras exista actos que conmocionen a la sociedad, por ello la labor preventiva es de vital importancia en la búsqueda de reducir los índices criminales tanto de la delincuencia común como la delincuencia de cuello blanco. Actualmente, la política criminal debe ir de la mano con las ciencias penales, ello en procura de lograr una toma de conciencia por parte de la sociedad, pero esto debe comenzar con la formación del individuo, desde la familia, la escuela y los centros de formación, la educación en valores es fundamental para prevenir la aparición de individuos que perviertan el sistema y causan un grave daño a la sociedad.

\section{Referencias}

- Caciagli, M. (1996), Clientelismo, Corrupción y Criminalidad Organizada. Evidencias empíricas y propuestas teóricas a partir de los casos italianos, Madrid: Centro de Estudios Constitucionales

- Ezaine, A. (1997), El proceso ejecutivo del delito - Autoría y participación, Lima: Ediciones Jurídicas Lambayecanas - Editora FECAT E.I.R.L.

- Frey-Rohn, L. (1993), De Freud a Jung, México: Fondo de Cultura Económica S.A.

- Hare, R. (1974), La Psicopatía - Teoría e investigación, Barcelona: Editorial Herder

- Muñoz, F. (1993), Derecho Penal - Parte General, Valencia: Editorial Tirant lo Blach

Fecha de recepción: 22 de mayo de 2020

Fecha de aceptación: 01 de junio de 2020 